\title{
OPTIMIZATION OF THE SUBJECT USERS SERVICE IN MOBILE INTERNET ENVIRONMENT ON THE LIBRARY WECHAT PUBLIC SERVICE PLATFORM
}

\author{
(C) Lin Zhang, 2019
}

Library of Dalian University of Foreign Languages, Dalian, Liaoning 11604, China

\begin{abstract}
The article thoroughly analyzes the use of WeChat public service platform in libraries and puts forward strategic ways for the development of users service by optimizing the orientation on individualized, open and interactive, specialized and integrated users service on definite subjects (SUS), and analyzes its optimization strategies connected with relationship, vitality and the quality. According to the analysis results, the author concludes that the optimization of SUS in mobile Internet environment should be based on the optimized service model of mobile service terminal platform, so as to realize the deepening of the function of SUS and the diversification of service forms.
\end{abstract}

Keywords: Mobile Internet, WeChat, Optimization, subject users service

Citation: Zhang Lin. Optimization of the Subject Users Service in Mobile Internet Environment on the Library WeChat Public Service Platform. Bibliosphere. 2019. № 1. P. 95-98. DOI: 10.20913/1815-3186-2019-1-95-98.

\section{Practical Background for Users Service Optimization in Mobile Internet Environment}

$\mathrm{M}$ obile Internet includes all mobile terminals in a broad sense. In the mobile Internet environment, there is a variety of micro-platforms for personalized services, such as MicroBlog, WeChat ${ }^{1}$, micro-video and so on. They provide tailored information services for their users through opening public accounts or platform Apps. Users can easily develop specialized functional services they need [1]. Many libraries in China have open WeChat services, ranging from bibliographic inquiry, renewal, applying for library cards, library news and simple information consultation [2]. Using Baidu Search Engine and taking Library and WeChat as the keywords, the author randomly searches out that 24 libraries have WeChat public service accounts, such as Tsinghua University, Shanghai Jiao Tong University and National Library of China. Through comprehensive search and help-services, the author finds that the current functional platforms of WeChat service in libraries are all in the form of public accounts, which integrate the short message service functions of mobile libraries and OPAC service acquisition function. They are all economical information service platforms designed by libraries. However, at present, the main application fields of Library WeChat are posting information, library catalogue retrieval, personal borrowing information checking and book reservation.

${ }^{1}$ WeChat - a mobile communicative system to transmit test and voice information, developed by the Chinease company Tencen (2011). Aplocation is available for iPhone, as well as phones running Android, BlackBerry, Windows Phone, Symbian and J2ME/S40. There is web-interface and client for PC.
It is short of interactive and deep information service functions. Meanwhile, finer and more intensive services are increasingly necessary for subject users service (SUS). They should be gradually deepened into users' scientific research activities by providing fast and professional, active, quick and interactive services [3]. Faced with the new form, SUS needs to use the open platform function of WeChat, accurately locating the users service function, and improving them in the mobile Internet environment through optimization strategies [4].

\section{Optimizing Location of Users Service in Mobile Internet Environment}

2.1. Individualization and open interactivity of SUS in mobile Internet environment

In the mobile Internet environment, SUS can be enhanced by personalized and open interactive service features with the help of WeChat's service functions. Its personalized function features originate from WeChat's one-to-one on-demand network transmission mode and highly centralized information. Initially WeChat's information service functions were mainly used to publish information and collect opinions with low publicizing cost and short-term rapid promotion. In the mobile Internet environment, the face to face on-demand network communication mode shows the immediacy of users service, which enables them to learn about the latest service developments. Open interaction requires librarians to constantly interact with users through the mobile Internet. Interaction is the driving force of SUS in mobile Internet, which will maintain the vitality of its service function. 


\subsection{Specialization of SUS service in mobile Internet environment}

Besides being individualized and open interactive, the service functions of WeChat are also stable and collective, which can group people, automatically match with $\mathrm{QQ}^{2}$ friends and mobile phone address book members. Its stability conforms to the service characteristics of specific user groups of SUS [5]. In addition, the WeChat system can automatically find people who open the same function in the vicinity according to the geographical location of users, so as to facilitate the collection of user groups. Establishing SUS WeChat Group is not only convenient for providing public information service to all users, but also providing specific contents to specific users by setting specific service user groups and using subject librarian-centered service model (Center-Bridge) to radiate information to marginal user groups. Tencent has officially pointed out that WeChat will provide a new interactive communication mode for users, media, enterprises, and create a new reading mode and experience through a free platform. The function orientation of this platform coincides with the purpose of subject service optimization under the mobile Internet environment.

\subsection{Integrated Functions of Subject service in Mobile Internet Environment}

In the mobile Internet environment, WeChat's indepth communication mode can help subject service to establish a direct relationship with users. After publishing information, it can collect opinions and suggestions, which will improve the loyalty of SUS. Especially in promoting the service relationship, it is more suitable to enhance its comprehensive function, mobilize the creativity of users, discover the real needs of users for subject service, and further ensure the accurate arrival and deep interaction of service information by WeChat [6]. In addition, the WeChat public platform has data analysis tools, which can analyze the information delivery rate, reading status and sharing status. SUS can achieve self-examination function by using WeChat data analysis tools, grasp the effects of SUS at the first time, systematically analyze the advantages and weaknesses of SUS, standardize and enhance comprehensive service functions.

\section{Optimizing strategies of SUS in mobile Internet environment}

In order to optimize SUS, we need to learn from the experience of the library's WeChat public account service functions, proceed from the optimization orientation of SUS by rationally using the WeChat functions and forming a distinctive form of subject users service, so as to realize the optimization its relationship, the vitality and the quality level.
3.1. Relying on the multi-functional WeChat to shape the image of SUS and improve its relationship

WeChat is a system possessing multi-functions with the core function, extended functions and additional functions. Its core function is to release and receive instant information. The extended functions include construction and maintenance of the interpersonal network, and its additional functions involve various mobile network applications. Dynamic subject users service has to make full use of the core function of WeChat to realize the face-to-face and instant one-to-many service form of subject users service, strengthen the communication with users by releasing and acquiring instant information, deal with the public opinion relationship on the periphery of subject service and feedbacks and complaints of loyal users timely to maintain the service image. In the process of interaction with users, a lively tone will be favored to promote the relationship with users and enhance the affinity of service and user participation.

Secondly, we use the extended and additional functions of WeChat to shape the image of subject service and build and maintain the interpersonal network between subject service and users. WeChat combines the advantages of various media (such as videos, pictures, voice message and searching, etc.) by using various technologies, realizes diversified network applications and produces strong integration effect. Subject service can use WeChat's multimedia applications to display contents and methods of subject service, summary and evaluation of activities to users. In the process of displaying information, it should be self-contained and provide linking services so that users can continue to understand other related subject service through links. But unlike real-time interactive communication, subject service platform in mobile Internet environment represents the overall image of subject service, and the content of service platform should pay attention to the seriousness and accuracy of information.

In addition, the voting function of WeChat is very simple and practical in the construction and maintenance of interpersonal network between subject service and users. It can collect users' opinions on relevant surveys extensively, which is conducive to the improvement of the quality and contents of subject service.

\subsection{Enhancing the Vitality of users service by using WeChat communication model}

The dissemination mode of WeChat presents the characteristics of «core-edge». With the disseminator as the core and the receivers of information gathered around it, a circle of information dissemination has been formed. With the "circle» dissemination of WeChat, both the F-F (face to face) service mode and the C-B (Center-Bridge) service mode 
can be directly implemented between subject service and users in mobile terminals. In recent years, in order to deepen the service, the subject service has introduced the embedded desktop service mode [7]. However, due to the influence of subject librarians' service consciousness, communicative skills, users' time and other factors, service development has been restricted in practice. However, in the mobile Internet environment, SUS can use mobile terminal and user access by using F-F service mode to communicate with users and understand their needs, sending relevant information to them to enhance the users' sense of identity and belonging. Relying on WeChat, C-B service mode will directly push information to the mobile terminal of user groups to arouse their interest. Various online and offline communication activities of WeChat can be carried out to distribute the subject service content of common theme to relevant users [8], enhancing the interaction and depth of subject service through user feedback, enriching subject service contents, improving the vitality of subject service, and achieving the service purpose of embedding user's academic activities (Fig.).

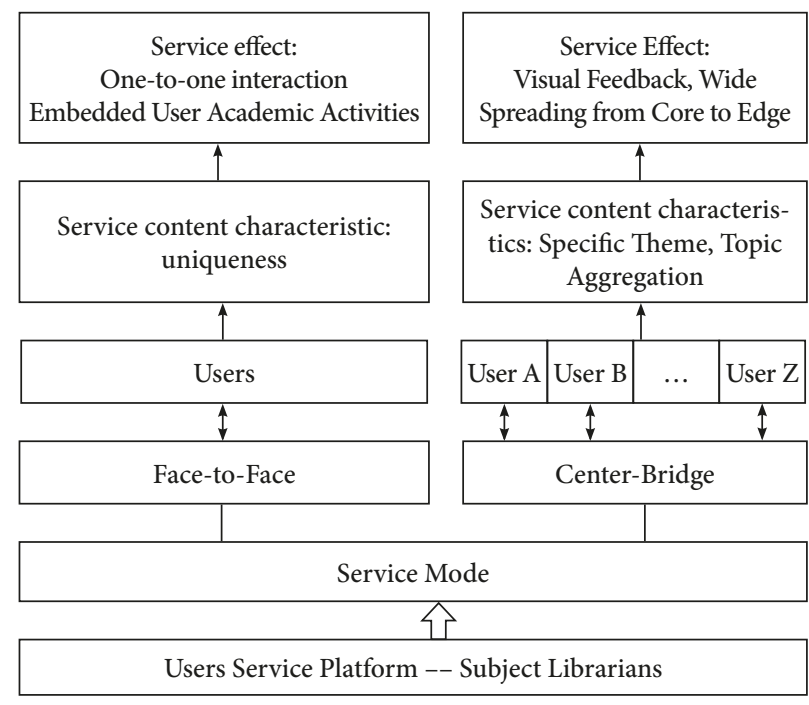

Fig. Users Service Circle Mode of Communication

\subsection{Deepening users service level based on the diversified pushing ways of WeChat}

Subject service in mobile Internet environment can use WeChat to establish user groups. Among the user groups with different subject backgrounds, SUS can provide different contents through WeChat platform, which will track and count the users' feedback about subject service. The contents and information should be diversified and constantly adjusted and enriched by reasonably integrating texts, pictures, videos and voice messages to improve users' experience feeling from a perceptual perspective. Based on the customer relationship management attributes of WeChat, one-to-one information is pushed to certain users so as to achieve accurate delivery of information.

Information push can adopt one-way subscription, catalogue selection, interactive communication, service application and hybrid mode. One-way subscription is the traditional push mode of SUS, which pushes these contents to users through WeChat, such as subject hotspots, academic research trends, subject database content updates, etc. Catalogue selection provides a catalogue for users first, pushing information contents of interest to users after their reply, which affords them more autonomous choosing space. Interactive communication mode utilizes the conversational function of WeChat to achieve one-to-one interaction with users. Deep-seated service is the requirement of users as well as one of the characteristics of subject service. Individualized service requirements are realized through interactive communication of WeChat to achieve the effect of deepening service. Service application mode will combine the relevant subject database providers or open access and WeChat platform together to push contents to users by positioning service technology to realize the mobile service of database push function [9]. The hybrid mode combines one-way subscription, catalogue selection, interactive communication and service application under the premise of mature single service to push subject service content for users. With broad and comprehensive qualities, this mode will realize all-round and free-selecting pushing service effect.

\section{Conclusion}

The optimization of users service in mobile Internet environment should be based on the information transmission characteristics of mobile phone service terminals. The mobile terminal service platform should be used to provide users service that conforms to the user's information behavior. At the same time, it is more important to optimize service mode relying on mobile terminal platform so as to realize subject service and deepen diversified service functions and forms.

\section{References}

1. 微信公众平台升级 9 大高级接口功能解 读_百度经验. http://jingyan.baidu.com/article/ e75aca85aabc13142edac688.html

2. Chen H., Zhu Ya. The ways of mobile information service of university library. Library Work and Study, 2013, 1, 39-42.

3. Xiao J., Huang L. Research on information service mode of the library based on WECHAT. Journal of Modern Information, 2013, 6, 55-57.

4. Wang J. [et al.]. Research on the micro-marketing of mobile information services in university libraries under the new media environment. Library Construction, 2013, 10, 45-49. 
5. Zhao L. J. The open and sharing mobile information service mode of university library. Library Work and Study, 2013, 1, 35-38.

6. Kong Yu. [et al.]. Research of library mobile information service based on Weixin public account. Journal of Intelligence, 2013, 9, 167-170, 198.

7. Chu J. Perception and elaboration of embedded services by subject librarians. Library \& Information Studies, 2012, 9, 1-8.
8. Li X., Li J. Accurate orientation of subject service objectives and accurate marketing of subject service. Researches on library Science, 2013, 9, 79-81.

9. Li Ch., Cui J., Chen Ch. Studies in the key technology of the big data knowledge service platform construction. Information and Documentation Services, 2013, 2, 29-34.

Recieved on Dec. 24, 2018 